\title{
INVESTIGATING THE EFFECT OF PRIDE, MINDFULNESS, GENERAL SELF-AWARENESS, EMOTIONAL SATISFACTION ON CUSTOMER CITIZENSHIP BEHAVIOR AMONG GREEN CUSTOMERS
}

\author{
Atousa Kamangar Rahmani ${ }^{1 *}$, Homa Heidari Navid ${ }^{2}$, Mayeseh Aman Zade Seyed ${ }^{3}$, Somayeh Ashouri ${ }^{4}$, Azadeh \\ Khalaji $^{5}$ \\ ${ }^{1 *}$ Department of Business Management, Faculty of Management, Islamic Azad University, Tehran, Iran; ${ }^{2} \mathrm{MBA}$ in \\ Global Business, Coventry University London Campus, London, England; ${ }^{3}$ Department of Business Management, \\ Faculty of Management, Economics and Accounting, Payame Noor University, Tehran, Iran; ${ }^{4,5}$ Department of Business \\ Management, Faculty of Management, Economics and Accounting, Payame Noor University, Tehran, Iran. \\ Email: ${ }^{1 *}$ a.kamangarrahmani@gmail.com, ${ }^{2}$ homa.heidarinavid@gmail.com, ${ }^{3}$ maysehamanzadehseyed@gmail.com, \\ 4smy_ashouri@yahoo.com, ${ }^{5}$ azadehkhalaji.8@gmail.com
}

Article History: Received on $19^{\text {th }}$ May 2021, Revised on $10^{\text {th }}$ June 2021, Published on $19^{\text {th }}$ June 2021

\begin{abstract}
Purpose of the study: The purpose of this study is to investigate the effect of pride, mindfulness, general selfawareness, emotional satisfaction on customer citizenship behavior among green customers.

Methodology: The present study is descriptive research in terms of applied purpose and duration of data collection. Structural equation modeling with Warp PLS software was used for analysis. Due to the survey and the lack of research, a questionnaire was used to collect data. The statistical population included customers of Cinere green products. Since their number is unknown, the infinite population was considered, and Cochran's formula for the endless population was estimated at 384 people.
\end{abstract}

Principal Findings: The results showed that pride has a positive and significant effect on the general self-awareness of green customers. Mindfulness has a substantial direct impact on the general self-awareness of green customers. The immediate effect of public awareness on the citizenship behavior of green customers was confirmed, and emotional satisfaction has a significant impact on the citizenship behavior of green customers. Finally, the mediating result of emotional satisfaction on the relationship between public self-awareness and citizenship behavior of green customers was confirmed.

Applications of this study: This research can be used in psychology and sociology areas.

Novelty/Originality of this study: to investigate the effect of pride, mindfulness, general self-awareness, emotional satisfaction on customer citizenship behavior among green customers.

Keywords: Pride, Mindfulness, General Self-awareness, Emotional Satisfaction, Customer Citizenship Behavior.

\section{INTRODUCTION}

Today, the green movement is so rapid that the phrase "forward to green" was searched 15.6 million times on Google in January 2008 and more than 31 million times in the two months following. Now, marketing agents and those involved in scientific centers are trying to identify and understand green customers and their needs while seeking to develop market reactions to these needs (Pourhossein, 2020). In this regard, customer behavior in organizations that deal with the client and the customer according to their activities is of great importance as much as their positive and constructive behaviors can help the organization achieve its goals, harmful and destructive behaviors. They can also disrupt the organization's activities. Citizenship behavior has been introduced as a voluntary practice of customers. Customer voluntary performance is defined as "voluntary and voluntary customer behaviors that improve service organizations' performance" (Ericson, 2014). Therefore, it is essential to study the green customer citizenship behavior and the factors affecting it.

According to previous studies, the variables of self-awareness, mindfulness, pride, and customer emotional satisfaction can play a significant role in directing green customer citizenship behavior. Self-awareness includes recognizing beliefs, thoughts, personality traits, emotions, personal values, biases, habits, weaknesses, strengths, as well as psychological needs that motivate human behavior. This affects the ability to identify the individual to respond to environmental cues and stimulate the individual's emotion in relating to others (Morin, 2011). Public self-awareness (PSA) affects people's social behaviors. This factor promotes voluntary and voluntary behaviors of consumers (Yi, 2008). Thus, public selfawareness as a psychological construct can lead to ethics and encourage activities related to ethical consumers. However, public awareness of the motivations and experiences of morality has not been sufficiently explored, let alone green literature (Pourhossein, 2020). Mindfulness is defined as follows: to pay attention in a special way that is goaloriented and in the current time with no judgment, which due to the critical role of attention, is sometimes translated as attention to consciousness (Karl, 2021). In the mind of consciousness, a person learns to be aware of his mental state at every moment and to focus his attention on his different mental states. In other words, mindfulness is a kind of consciousness that arises through non-judgmental awareness and with the intention of the present moment (Kabat-Zinn, 2021). Pay attention to anything, especially those aspects of life that human beings value most. Mindfulness, along with 
cognitive processes, specifically and seriously focuses on emotions, emotions, which is one of the most important factors influencing the quality and satisfaction of relationships. Therefore, using these approaches improves emotion processing and emotion regulation and improves emotional skills (Morledge, 2013).

Self-conscious emotions include guilt, embarrassment, pride, shame and deal with self-assessment processes creating behavioral criteria (Kim, 2011). Such emotions strengthen people's understanding and evaluation of themselves. Since this kind of emotion includes moral aspects, it provides honest identities and images in cultures (Holmstrom, 2021). Pride, as a self-centered emotion, is closely related to a person's inner state and characteristics, reinforcing positive emotions and differentiation. It is consistent with the individual's knowledge, expressions, and experiences (Isturiz, 2021). Pride increases awareness because it emphasizes individual differentiation through social comparison (Pfattheicher, 2015). Self-awareness is enhanced by comparing personal standards and is accompanied by self-regulation and ostentation (Beach, 2021). Meanwhile, Pride leads to the adjustment of subjective criteria, which leads to more active behaviors (Sánchez-García, 2021). Pride-induced self-awareness leads consumers to choose according to their goals (Vago, 2012). Pride is able to facilitate special social results as well as adaptive behaviors versus negative emotions, thus it will be made more appropriate for social behaviors as a complex element of social functioning (Wilcox, 2011). Pride differs from self-expression due to its close connection with self-awareness and motivates the individual to reach their social goals and to satisfy social needs. It is sensed when people assess the events or stimuli following their identity objectives (Huang, 2019).

Satisfaction is defined in terms of process and outcome. Process satisfaction is determined by the expectationsatisfaction model (Bull, 2021), while definitions of satisfaction result express the realized situation about arousal and reinforcement of need. Satisfaction with the result is described as "a desirable level of consumption realization." This ultimate satisfactory situation is more suitable for consumer satisfaction with services. Accordingly, the present study focuses on emotional satisfaction as per definitions of a good outcome. Consumer satisfaction is the satisfaction of satisfying personal value, not cognitive satisfaction, based on perceived value calculation (Brandtner, 2021) because personal evaluation evokes positive emotions (Shang, 2019). Consumer satisfaction with the performance of the product/service depends on whether they perceive the feeling of either satisfaction or dissatisfaction regarding the performance of the service/product according to the provider or themselves (Anderson, 2020). Because green consumption embraces consumers' values and makes them proud, their satisfaction with the ethical performance of the product/service may have a more significant impact on their citizenship behavior (Pham, 2010).

Organizations, including firms, are turning to green marketing because of the pressure of government regulations, improving health, employee health, reducing the exorbitant costs of pollution control at the bottom of the production line, and countering competitors' green measures. On the other hand, there are consumers who, in their purchasing behavior, examine the impact of the manufacturing and consumption process of goods on the environment and, based on this, select products that are superior in meeting environmental responsibilities (Yamaguchi, 2021). The increase in the number of such consumers, called green consumers, has led marketers to target the green market segment (Al-Azzam, 2021; Wilcox, 2011). In this regard, since mindfulness and pride lead to promote social behaviors and self-awareness, the present study examines the effect of customer pride (as a sense of self-awareness) and mindfulness (as a crossroad between self and others) on citizenship behavior. The green customer pays for green consumption. This study tries to provide theoretical, functional, and practical insights regarding green consumers through investigating the consequences and backgrounds of green consumption at the same time, while the importance of green consumption has doubled the need for such a study.

\section{The rationale of the study}

Given what has been said and the lack of research on the role of mindfulness interventions in making changes in desirable and undesirable behaviors of customer behavior, this study aims to evaluate the effect of mindfulness-based cognitive model appropriate to Iranian culture in changing customer citizenship behaviors. Check the green. Given that many services of organizations are delivered directly in person for other customers, even in lack of interaction between the customers, such a presence affects the other customers' attitude and behavior towards the organization.

\section{The aim and objective of the study}

The present study aims to examine the various factors affecting the citizenship behavior of green customers to gain a clear understanding of such factors and customers who adopt these behaviors. As a result, considering customers' importance among service-delivering organizations and the quality of their behaviors, as well as the absence of a comprehensive model in developing factors affecting the green customers' citizenship behavior, the main issue of this study is "identifying factors affecting the citizenship behavior of green customers."

\section{LITERATURE REVIEW}

\section{The theoretical framework of research}

The present study has developed a green consumer general self-awareness model based on pride and mindfulness as backgrounds of public self-awareness and green customers' emotional satisfaction and citizenship behavior as consequences of green consumption based on Huang and Li's (2019) research. 


\section{Public pride and self-awareness}

Self-conscious emotions, such as pride, guilt, shame, and embarrassment, involve self-assessment processes that create behavioral criteria (Kim, 2011). They strengthen people's understanding and evaluation of themselves. As self-conscious emotions encompass moral aspects, they represent honest images and identities in cultures. Pride, as a self-centered emotion, is closely related to a person's inner state and characteristics, reinforcing positive emotions and differentiation (Yang, 2021). It is consistent with the individual's awareness, expression, and experiences. Pride increases awareness because it emphasizes the distinctiveness of individuals through social comparison (Huang, 2019). Self-awareness is enhanced by comparing oneself with personal criteria and is associated with self-regulation (Wilcox, 2011) and ostentation. Pride, meanwhile, leads to self-adjustment and personal standards, which in turn leads to more active behaviors. (Wilcox, 2011) found that arrogant self-awareness leads consumers to choose according to their goals.

Pride is able to facilitate special social results as well as adaptive behaviors versus negative emotions, thus it will be made more appropriate for social behaviors as a complex element of social functioning. According to its close connection with self-representation and self-awareness, pride differs from basic emotions and motivates one to reach social goals and to satisfy social needs. It is sensed when people evaluate events or stimuli according to their identity objectives, whereas negative self-awareness feelings (for example, guilt and shame) assess them according to their identity objectives (Huang, 2019).

Pride aids in ethical decisions, such as allocating resources among group members (Huang, 2019). It also mediates passion and moral Behavior (Horberg, 2011). Although pride is associated with indifference, hierarchy, and social status, this is achieved through positive evaluation and goal-based self-esteem. Ethical consumption involves purposeful, longterm, and short-term behavior requiring complex decision-making that requires time and energy to search for information and choose between different ethical behaviors. Green customers are looking for time-consuming and challenging information to reach long-term value. As an example, customers seek information regarding green restaurants, including their locations, actions, and menus, and verify the claims and authenticity of the green restaurant. In addition, they should decide to visit green restaurants if necessary due to the harmful effects of travel on the environment. Within such ethical-type consumption processes, the ethical users may be proud of their purpose and achievement of their life via ethical purchases, which in some cases may require a lot of effort and problem-solving processes (Huang, 2019).

The pride is considerably sensed in case of publicly known superior performance or outcomes. Williams and Desanto emphasized that pride, as a self-conscious social emotion, is recognized when it places itself in a relatively stable position based on the evaluations of others. Panagopoulos stated that pride is linked to public self-awareness because people worry about the public self, which others value. It owns an informational function to present an individual's social, acceptance and value. To maintain positive self-esteem and respect for others, pride leads to social behaviors, improving social quality and acceptance. Pride leads people to search for either interpersonal or social bonds and promotes future pious behaviors such as social behaviors. The theory of personality change states that personality change that reduces personal and public awareness does not lead to antisocial behaviors. In particular, a decrease in emotional self-awareness is due to an increase in group cohesion with a reduction of private standards and norms.

In contrast, reducing public awareness is due to anonymity and scattered responsibility with a decrease in concern for evaluating others. Accordingly, pride is more related to public attention, which is focused on the evaluation of others. Thus, the pride experienced by the assessments of others creates a general awareness that focuses on the review of others. As a positive social self-awareness emotion, pride may be an essential prelude to public understanding of consuming green restaurants as social behavior. It stimulates public self-awareness and manages the management of self-awareness as acceptance and social value. The sociality and positive assets of pride lead to arrogant social behaviors in the future and thus drive public awareness and a constant visit to green restaurants as the most dynamic behaviors of the end (Huang, 2019).

\section{Mindfulness and general self-awareness}

As the combination of meditation-based mindfulness and contemporary psychological practices, mindfulness has attracted considerable attention regarding the progress in psychological function and well-being (Anaza, 2014). The meditation practices which are based on mindfulness result in enhanced compassion and empathy (Huang, 2019). In addition, mindfulness is defined as follows: a state of consciousness drawing attention and awareness to the present moment and creates a non-judgmental and conscious awareness of the momentary experience of the environment (Aguado, 2011), thoughts, feelings, and actions of the individual (Morin, 2011). The two fundamental aspects of mindfulness include self-awareness of internal states, behaviors, experiences, and external facts and experiences (Huang, 2019). Mindfulness develops self-awareness, self-control, and positive interpersonal relationships, which enhance social behaviors (Vago, 2012). The mindfulness literature presents controversial empirical findings on the relationship between mindfulness and self-awareness. However, most studies theoretically emphasize that mindfulness results in selfawareness. Hence, more studies are required to examine the relationship between self-awareness mindfulness (Baciadonna, 2021). 
Conscious consumers tend to be concerned and aware of the consequences of their consumption in terms of environmental impacts (Huang, 2019), and mindfulness is positively associated with environmentally responsible Behavior (Schuman-Olivier, 2020). Personal self-awareness and public self-awareness increase access to information about oneself, and public self-awareness focus on self-knowledge based on insight into oneself as a social object. Mindfulness leads to general self-awareness by guiding it towards the internal aspects, expanding the inner selfawareness to the awareness of external realities (Massari, 2021), integrating internal and external experiences, and interacting with other people, activities, and the world (Huang, 2019).

Mindfulness encompasses empathy and self-observation as integral elements. The very emotional or emotionally vulnerable empathetic people tend to be affected by social assessments. Empathy seemingly owns a significant relationship with public and private self-awareness. Self-awareness of empathic people raises concerns about their feelings, while their general self-awareness raises concerns about the feelings and evaluations of others (Tee, 2021). People with public self-awareness show more adaptation to group pressures and very valuable social acceptance. Beetle et al. reported that mindfulness and self-awareness are considerably correlated. In addition, mindfulness and general selfawareness are more strongly correlated because self-awareness

Publicity includes attention not only to oneself but also to oneself as a social object seen by others. In addition, they argued that general self-awareness, as self-awareness about the perception of others, is similar to mindfulness, which focuses on one's relationships with others (Huang, 2019).

\section{General self-awareness and emotional satisfaction}

Public awareness stimulates financial aid when people are under the supervision of others, and that self-awareness increases assistance to others. Also, because public awareness motivates a person to feel positive, even when consumers are in a situation of private financial aid, it leads to charitable behaviors. Ethical consumers may increase their moral behaviors (Page, 2021) and inclinations when visiting green restaurants, which can be considered as behaviors in a public place. Accordingly, the visit of ethical consumers to green restaurants increases public awareness, which may lead to a positive self-assessment and an increase in focus on their long-term values and motivations. Lead a positive effect. Satisfaction is defined from two perspectives: process and result or performance. Process satisfaction is determined by the expectation-confirmation model, while definitions of performance satisfaction express the state of accomplishment associated with arousal and reinforcement. Oliver described performance satisfaction as "a desirable level of consumption-related realization." This final satisfactory situation is more suitable for consumers' satisfaction with the services. Accordingly, this study focuses on emotional satisfaction based on definitions of performance satisfaction. Consumer satisfaction is the satisfaction of satisfying personal value, not cognitive satisfaction, which is based on the calculation of perceived value, because unique value creates positive emotions (

In addition, consumer satisfaction is based on performance, which is primarily attributed to their success/failure in the version of the product or service. Consumer satisfaction with the performance of a product/service depends on whether they perceive the provider or themselves as feeling satisfied or dissatisfied with the performance of the product/service. Because ethical consumption embraces consumers' values and makes them proud, their satisfaction with the honest understanding of the product/service may be influenced by intrinsic affiliation. Because both public and private selfawareness enhance inherent causal characteristics, consumer satisfaction is affected by their self-awareness (Huang, 2019). Thus, the general self-awareness of moral consumers can lead to emotional fulfillment.

\section{Public self-awareness, emotional satisfaction, and citizenship behavior of green customers}

People with high public awareness tend to worry about how others perceive them. In the presence of others, people have a problem with public awareness that they are not worried about what others will perceive. Leary and Kowalski argue that in case of willingness for making good impressions, the individuals deliberately seek related cues to create a good feeling in front of others. Krishnan and Areva stated that intense concern for preserving a favorable public image leads to more organizational citizenship behavior similar to customer citizenship behavior. They also found that public awareness is an essential predictor of leaders' organizational citizenship behavior, while self-monitoring did not predict organizational citizenship behavior. Management theory states that people with high perception management motivations try to avoid negative influence on others and tend to engage in citizenship behavior to improve their reputation and benefit others. Grant and Meyer found that management motivation positively affects the positive relationships between social motivation and citizenship behavior. Green customers' general awareness may increase in the presence of other customers and service employees, leading them to manage their perceptions. Accordingly, they may engage in customer citizenship behavior to assist green restaurants, in which ethical customers satisfy their moral values as social and private ones. The citizenship behavior of green customers can serve as indicators to make good impressions before others, including service employees and other customers. Accordingly, as Bolino stated that perception management tends to exhibit citizenship behavior, green customer public awareness, which is closely related to perception management, may significantly enhance customer citizenship behavior. Existing studies provide evidence to prove satisfaction as the primary motivator of loyalty and the goals of word of mouth. However, consumers can do more advanced activities than loyalty and word of mouth to support their manufacturers or service providers. Bettenctor defined voluntary customer performance as "beneficial and voluntary customer behaviors that support the company's 
ability to provide quality service." More recently, it has been called customer citizenship behavior, which is similar to organizational citizenship behavior and various other terms, such as voluntary customer behavior, voluntary customer performance, and out-of-customer behaviors (Huang and Li, 2019), and these draw attention to have attracted (Anaza, 2014). Customer Citizenship Behavior points to the "voluntary behavior of specific customers that is nor directly neither explicitly rewarded or expected, however, generally leads to higher quality services and promotes the adequate performance of service-delivering organizations (Huang and Lee, 2019). It was argued that customer citizenship behavior is essential for service companies because service providers deal with some challenges in achieving significant productivity via capital substitution (Huang, 2019).

Satisfaction is usually considered one of the backgrounds of customer citizenship behavior, including empathy (Anaza, 2014), customer sociability, customer and company identification relationship, customer commitment, and customers who have social-emotional support and tools from other customers. Social exchange theory implies that individuals must commit to reciprocity while enjoying others. Customer and service companies' relationships can be considered a social exchange, which builds trust and mutual communication. Groot reported that customer satisfaction with services encourages them to benefit from service citizenship by engaging in customer citizenship behavior. Benktor found that customer satisfaction positively affects customer citizenship behavior, and Yi and Gong also found a positive impact on customer citizenship behavior (Huang, 2019). Kim et al. (2012) found that improved customer service satisfaction was positively associated with loyalty and participation in customer citizenship behavior (Kim, 2011). Groot reported that customer satisfaction has a stronger relationship with customer citizenship behavior than customer socialization (Huang, 2019). Empirically, Anaza (2014) reports that the emotional satisfaction of customers positively influences citizenship behavior in the online purchase (Anaza, 2014). Furthermore, Chen et al. (2010) considerably influenced customer satisfaction with customer citizenship behavior through delivering beauty and fashion services as well as services for the reputed Taiwanese online community (Anaza, 2014). In line with the theoretical framework, the conceptual model and research hypotheses are as follows:

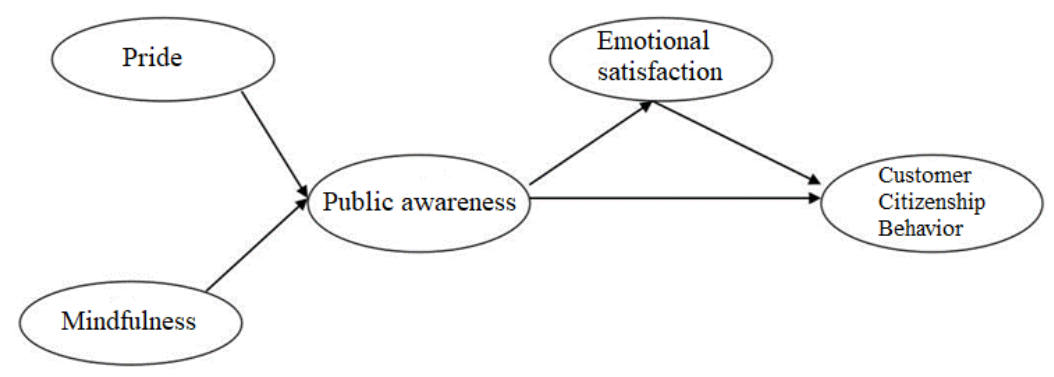

Figure 1: Conceptual model of research

Source: $\underline{\text { Huang, 2019) }}$

Hypothesis 1: Pride has a significant effect on the general self-awareness of green customers.

Hypothesis 2: Mindfulness has a significant effect on the general self-awareness of green customers.

Hypothesis 3: Public awareness has a significant effect on the citizenship behavior of green customers.

Hypothesis 4: Emotional satisfaction has a significant effect on the citizenship behavior of green customers.

Hypothesis 5: Emotional satisfaction has a significant mediating effect on public self-awareness in green customers' citizenship behavior.

\section{METHODOLOGY}

This research is descriptive-applied survey research. The statistical population of the study includes customers of Cinere green products, whose number is unlimited. Using the sampling formula from the statistical population, 384 people have been determined as the sample size. The study sample will be available by the method. It is called purposive sampling, which is a sample that includes anyone who happens to be present at the time of sample selection. The research assessment tool is a standard questionnaire taken from the study of Huang and Li (2019). The technical questions section also includes questions related to research variables and has a five-point Likert scale (from very low to very high). Table 1 summarizes the question variables for all sections.

Table 1: Information of specialized questions of the questionnaire

\begin{tabular}{lll}
\hline Questionnaire source & Variable / Dimension & Number of questions \\
\hline \multirow{3}{*}{ (Huang, 2019) } & Pride & 3 \\
\cline { 2 - 3 } & Mindfulness & 9 \\
\cline { 2 - 3 } & Public Awareness & 3 \\
\hline
\end{tabular}


Emotional satisfaction 3

Citizenship behavior 7

One of the main goals in setting up any test or questionnaire is its high validity. In the present study, the questionnaire questions are tailored to the theoretical foundations and according to the quality of academic and operational definitions of each of the indicators, scales, and variables, and to determine the validity of the content of the advice of professors, experts and researchers in the relevant field. The research subject who were aware of this field was used, and the validity of each of the questions and structures was examined. Then, upon approval of the questionnaire by the experts, the questionnaires were completed among the statistical sample of the research. In the present study, Cronbach's alpha method was used to calculate the reliability of the questionnaires using SPSS statistical software. In the present study, both descriptive and inferential statistics are used to analyze the data. Thus, after extracting the questionnaire data, first, for demographic studies, descriptive methods were used with SPSS software about the studied variables. Then to answer the research questions, inferential statistics with PLS software were used. WARP-utilized.

\section{FINDINGS}

The structural model analysis test with PLS software was used in order to analyze the research hypotheses. The level of significance is the criterion for confirming or rejecting the idea. The standard for approving and rejecting the views of the significance level is 0.05 ; if the significance level is less than 0.05 , that hypothesis will be confirmed. Figure 2 shows the effect of research variables on each other.

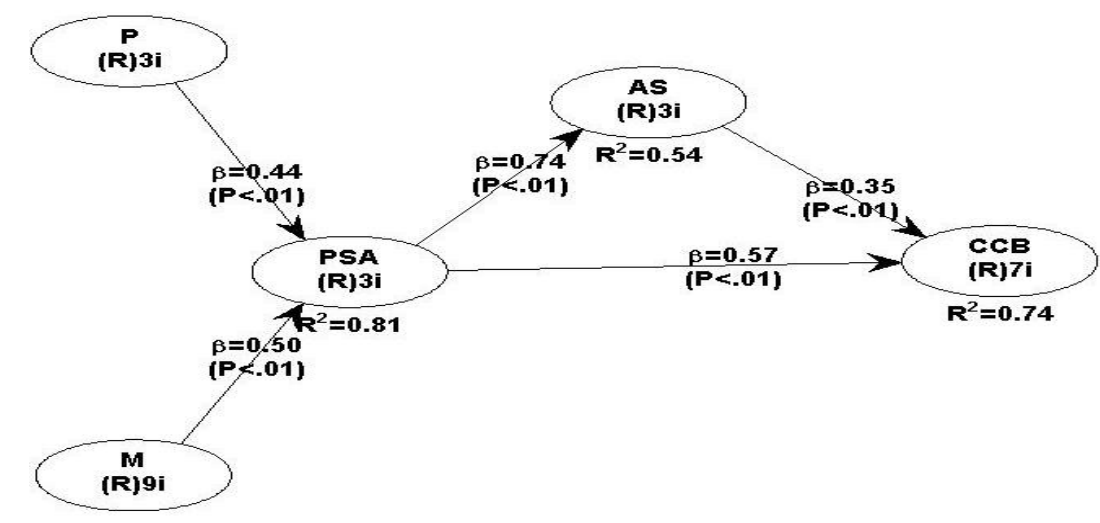

Figure 2: Results of estimating the pattern of structural equations of research in warp PLS software

The path coefficient shows a linear causal relationship and the intensity and direction of this relationship between the two variables. The regression coefficient is standard. It is a number between -1 and +1 , which, if equal to zero, indicates the absence of a linear causal relationship between the two latent variables.

Table 2: Validity and reliability

\begin{tabular}{llllll}
\hline Variables & Name in the model & Cronbach's alpha & CR & AVE & Result \\
\hline Pride & P & 0.859 & 0.915 & 0.782 & Suitable \\
\hline Mindfulness & M & 0.920 & 0.934 & 0.612 & Suitable \\
\hline Public Awareness & PSA & 0.873 & 0.873 & 0.697 & Suitable \\
\hline Emotional satisfaction & AS & 0.876 & 0.876 & 0.701 & Suitable \\
\hline Citizenship behavior & CCB & 0.921 & 0.921 & 0.626 & Suitable \\
\hline
\end{tabular}

In the evaluation stage of the structural model, the suitability of the model should be checked so that the results of the hypotheses can be considered reliable.

In the software Warp PLS, there exists three indicators for the model's suitability:

- The significance level (p) for the mean path coefficient needs to be lower than 0.05 .

- The significance level (p) for the modified coefficient of determination needs to be lower than 0.05.

- Mean-variance inflation factor: Multiple alignment intensity is evaluated by a variance inflation factor in the leastsquares regression analysis. It explains how much of the change in the estimated coefficients for alignment has increased. The magnitude of the VIF value analyzes the intensity of multiple lines. As a rule of thumb, a matter of AVIF less than 5 indicates the non-significance of multiple lines.

The values related to the results of model fit indices are presented in Table 3: 
Table 3: Fitness indices

\begin{tabular}{llll}
\hline The main criteria & $\begin{array}{l}\text { The value of the research } \\
\text { model }\end{array}$ & Acceptable amount & Result \\
\hline Average path coefficient & $\mathrm{p}<0.001(0.519)$ & $\mathrm{p}<0.05$ & Confirmation \\
\hline $\begin{array}{l}\text { The adjusted coefficient of } \\
\text { determination }\end{array}$ & $\mathrm{p}<0.001(0.697)$ & $\mathrm{p}<0.05$ & Confirmation \\
\hline $\begin{array}{l}\text { Mean-variance inflation } \\
\text { factor }\end{array}$ & 2.676 & $-<5$ & Confirmation \\
\hline Additional criteria & $\begin{array}{l}\text { The value of the research } \\
\text { Model }\end{array}$ & Acceptable amount & Confirmation \\
\hline GOF & 0.690 & $\begin{array}{l}\text { small }>=0.1, \text { medium }>=0.25, \\
\text { large }>=0.36\end{array}$ & Confirmation \\
\hline srmr & 0.094 & acceptable if $<=0.1$ & Confirmation \\
\hline Smar & 0.074 & acceptable if $<=0.1$ & . \\
\hline
\end{tabular}

Table 3 shows that the significant level values for the mean path coefficient and the mean determination coefficient are less than 0.05, and the mean-variance inflation factor is less than 5, which indicates a good fit of the model. Therefore, we can conclude that the research model fits well, so it is approved. After confirming the model, structural analysis results can be used to test hypotheses and interpret them. Power forward The model is examined through the coefficient of determination (R2). Such a coefficient is employed to show the extent of either dependent variable variance or variance which is explained through a complex of independent variables. The value of this criterion fluctuates between zero and one. The closer the importance of this criterion is to one, the independent variables predict a large amount of variance of the dependent variable. The closer this value is to zero, the less the dependent variable changes are more minor. It has not been independent of its research literature. Values above 0.33 are considered a medium to high predictive power (Rasouli et al., 2019).

Table 4: The predictive power of the research model

\begin{tabular}{llll}
\hline Variables & Model in the model & The amount of predictive power & Result \\
\hline Public self-awareness & PSA & 0.806 & Suitable \\
\hline Emotional satisfaction & AS & 0.543 & Suitable \\
\hline Green citizenship behavior & CCB & 0.744 & Suitable \\
\hline
\end{tabular}

Considering that all the coefficients of Table 4 are at the desired level, the model has the necessary capacity and predictive power.

Table 5: Multivariate Regression Results of Investigation Hypotheses

\begin{tabular}{lllll}
\hline Direction & Path coefficient & Amara t & Significance level & Result \\
\hline The first assumption & 0.442 & 9.215 & $\mathrm{p}<0.000$ & Confirmation \\
\hline The second assumption & 0.497 & 10.428 & $\mathrm{p}<0.000$ & Confirmation \\
\hline The third assumption & 0.570 & 12.085 & $\mathrm{p}<0.000$ & Confirmation \\
\hline The fourth assumption & 0.351 & 7.22 & $\mathrm{p}<0.000$ & Confirmation \\
\hline The Fifth assumption & 0.259 & 6.492 & $\mathrm{p}<0.001$ & Confirmation \\
\hline
\end{tabular}

We use the Sobel test to examine the mediating role of emotional satisfaction.

Upon Sobel's test, a Z-value is yielded through the following equation. If this value is more significant than 1.96 can be confirmed at the level of $95 \%$ significance of the mediating effect of a variable.

$$
z-\text { value }=\frac{a \times b}{\sqrt{\left(b^{2} \times s a^{2}\right)+\left(a^{2} \times s b^{2}\right)+\left(s a^{2} \times s b^{2}\right)}}
$$

The value of the path coefficient between the mediating and independent variables.

b: The value of the path coefficient between the dependent variables and the mediator.

sa: The standard error for the path between the mediator and independent variable.

sb: The standard error for the path between the dependent variable and mediator.

Hypothesis 5: Emotional satisfaction has a significant mediating effect on public self-awareness in green customers' citizenship behavior. 
Table 6: Multivariate regression results of the fifth hypothesis with Sobel test

\begin{tabular}{llllll}
\hline Direction & $\begin{array}{l}\text { Path } \\
\text { coefficient }\end{array}$ & $\begin{array}{l}\text { Amara } \\
\boldsymbol{z}\end{array}$ & $\begin{array}{l}\text { standard } \\
\text { error }\end{array}$ & $\begin{array}{l}\text { Significance } \\
\text { level }\end{array}$ \\
\hline $\begin{array}{l}\text { The path of general self-awareness on emotional } \\
\text { satisfaction }\end{array}$ & 0.737 & 15.995 & 0.046 & $\mathrm{p}<0.001$ \\
\hline $\begin{array}{l}\text { The path of emotional satisfaction on green } \\
\text { citizenship behavior }\end{array}$ & 0.351 & 7.228 & 0.049 & $\mathrm{p}<0.001$ \\
\hline $\begin{array}{l}\text { Sobel test results in the path of general self-awareness } \\
->\quad \text { Emotional satisfaction -> Green citizenship } \\
\text { behavior }\end{array}$ & 0.259 & 6.492 & 0.041 & $\mathrm{p}<0.001$ \\
\hline
\end{tabular}

Based on the results obtained from Table 6, the effect of emotional satisfaction on the relationship of public selfawareness on the citizenship behavior of green customers is smaller than the default value $(\mathrm{p}<0.05)$ and shows passionate pride in the relationship of public self-awareness. It has a significant mediating effect on the citizenship behavior of green customers.

\section{DISCUSSION}

The conceptual model of Huang and Li (2019) was used in this research in order to analyze the relationships of research variables. In this study, we examined the effect of pride, mindfulness, general self-awareness, emotional satisfaction on customer citizenship behavior among green customers in Cinere products. In the first stage, the structures of pride, selfawareness, mindfulness, and green behavior are explained in more detail, and hypothetical, theoretical relationships are presented according to the background of the existing literature and the focus of our research in the Cinere product stores (Huang, 2019).

As mentioned in the results of Table 5, in connection with the first hypothesis, the results show that pride has a significant effect on the general self-awareness of green customers. The magnitude of this effect is 0.442 , indicating that a unit of increase in satisfaction increases public awareness by 0.44 . The results of the first hypothesis confirmed by the studies of (Huang, 2019; Wilcox, 2011) are also consistent in their studies. In internal investigations, no background has been found that examines the direct relationship between pride and public self-awareness of the customer. This study and its results can be a new bridge in the literature of public customer awareness in Iran. Therefore, the pharmaceutical company must be able to create self-awareness for customers in various ways. As mentioned in Table 5, in connection with the second hypothesis, the results show that mindfulness has a significant effect on the general self-awareness of green customers. The magnitude of this effect is 0.497 , indicating that a unit of increase in mindfulness increases public awareness by as much as 0.49 . The results of the second hypothesis confirmed are consistent with the studies of (Huang, 2019; Sánchez-García, 2021; Wilcox, 2011). In their studies, they also found a direct relationship between mindfulness and general self-awareness in customers. In internal studies, a background that examines the direct connection between the mind Consciousness and public self-awareness of the customer was not found. This study and its results can be a new bridge in the literature of general customer self-awareness in Iran. As mentioned in Table 5, in connection with the third hypothesis, the results show that public awareness has a significant effect on the citizenship behavior of green customers. The magnitude of this effect is 0.570 , indicating that a unit increase in public awareness increases green citizenship behavior by 0.57 . Results of the third hypothesis confirmed by studies of (Huang, 2019; Sánchez-García, 2021; Wilcox, 2011) are consistent. In their studies, they also found a direct relationship between public awareness and green behavior in customers.

On the other hand, in their study, Zamanhani et al. (2014) pointed to the relationship between self-awareness and citizenship behavior, not from the customer type but the open organizational type; they have also extracted this positive relationship in their study. As mentioned in Table 5, in connection with the fourth hypothesis, the results show that emotional satisfaction has a significant effect on the citizenship behavior of green customers. The magnitude of this effect is 0.351 , indicating that a unit increase in emotional satisfaction as much as 0.35 increases green citizenship behavior. The results of the fourth hypothesis confirmed are consistent with studies by (Gupta, 2012; Han, 2020). In their studies, they also found a direct relationship between emotional satisfaction and green behavior in customers. Of course, (Dinpanah, 2019) also extracted the relationship between the general type of satisfaction and citizenship behavior positively and directly. This source can be considered a citation because emotional satisfaction can be part of public satisfaction. As mentioned in Table 5, in connection with the fifth hypothesis, the results show that emotional satisfaction has a significant mediating effect on the relationship between public self-awareness and citizenship behavior of green customers. The results of the fifth hypothesis confirmed are consistent with the studies of (Cop, 2020; Huang, 2019). We could only refer to one source in this hypothesis because the basis of our model design was the study of (Huang, 2019). Only in this study, these three paths between self-awareness, satisfaction, and green Suhrawardi behavior have been examined. The foreign research was on one side.

Regarding the hypotheses of this study, it can be said that pride increases awareness because it emphasizes the characteristic of differentiating people through social comparison. Self-awareness is enhanced by comparing oneself with personal criteria and is accompanied by self-regulation and ostentation. Pride, meanwhile, leads to self-adjustment 
and personal standards, which in turn leads to more active behaviors. This study concluded that self-awareness due to pride leads to consumers choosing according to their goals. Satisfaction can facilitate specific social outcomes and adaptive behaviors compared to negative emotions, making it more appropriate for social behaviors as a complex component of social functioning. Based on its close connection with self-awareness and self-representation, Pride differs from basic emotions and motivates one to achieve one's social goals and serve social needs. Pride is felt when people evaluate stimuli or events following their identity goals. At the same time, negative self-awareness feelings (shame, guilt, and embarrassment, e.g.) assess them pursuing their identity goals. A high level of pride is experienced when superior performance or results are publicly known. Satisfaction is linked to public self-awareness because people tend to worry about the public self, which is valued by others. Pride has an informational function of presenting one's social status, acceptance, and value. To maintain positive self-esteem and respect for others, pride leads to social behaviors, improving social quality and acceptance. Pride leads people to seek interpersonal or social bonds and promotes future pious behaviors such as social behaviors. The theory of personality change states that personality change that reduces personal and public awareness does not lead to antisocial behaviors. In particular, a decrease in emotional self-awareness is due to increased group cohesion with a reduction in private standards and norms. In contrast, a decline in public awareness is due to anonymity and scattered responsibility, with a decrease in concern for evaluating others.

\section{CONCLUSION}

According to our results, pride is more related to public awareness, which is focused on the evaluation of others. Thus, the satisfaction experienced by the assessments of others creates a general understanding that focuses on the review of others. In line with the results of this study, it can be stated that mindfulness can be defined as a state of consciousness that draws attention and awareness to the present moment and non-judgmental and conscious awareness of the momentary experience of the environment. , Creates a person's thoughts, feelings, and actions. Develops mindfulness, self-awareness, self-control, and positive interpersonal relationships, which Increases social behaviors. The mindfulness literature presents controversial empirical findings on the relationship between mindfulness and self-awareness. However, most studies have theoretically emphasized that mindfulness leads to self-awareness. Therefore, more studies are needed to examine the relationship between mindfulness and self-awareness. Environmentally responsible behavior is positively related. Personal self-awareness and public self-awareness increase access to information about oneself, and public self-awareness focus on self-knowledge based on insight into oneself as a social object. Mindfulness leads to general self-awareness by directing it towards internal aspects, expanding inner self-awareness to awareness of external realities, integrating internal and external experiences, and interacting with other people, activities, and the world. Studies have shown that public awareness stimulates financial aid when people are under the supervision of others, and self-awareness increases assistance to others. Because public awareness motivates a person to feel positive, even when consumers are in a situation of private financial aid, it leads to charitable behaviors. Ethical consumers may increase their moral behaviors and inclinations when visiting green centers, which can be considered behaviors in a public place.

Accordingly, the visit of ethical consumers to green centers increases public awareness, which may lead to a positive self-assessment and increase the focus on their values and long-term motivations, and thus to an effect. Lead positively. In addition, consumer satisfaction is based on performance, which is the main reason for their attribution to success/failure in the version of the product or service. Consumer satisfaction with the performance of a product/service depends on whether they perceive the provider or themselves as feeling satisfied or dissatisfied with the performance of the product/service. Because ethical consumption embraces consumers' values and makes them proud, their satisfaction with the honest account of the product/service may be more influenced by intrinsic causality. Since both private and public self-awareness enhances inherent causal characteristics, consumer satisfaction is affected by their self-awareness. Thus, the general self-awareness of ethical consumers can lead to emotional satisfaction, which has been confirmed in this study.

\section{LIMITATION AND STUDY FORWARD}

Since the statistical population was so wide and we just were able to cover few provinces of Iran, we suggest to all areas of the country and compare the findings.

\section{ACKNOWLEDGEMENT}

Hereby, we deeply appreciate the kind collaboration of all participants.

\section{AUTHORS CONTRIBUTION}

The operational phases of the present study were carried out by Atousa Kamangar Rahmani and the rest of the authors were in charge of monitoring the research process.

\section{REFERENCES}

1. Aguado, E., Milosevic, Z., Hernández, C., Sanz, R., Garzon, M., Bozhinoski, D., Rossi, C. (2011). Functional Self-Awareness and Metacontrol for Underwater Robot Autonomy. Sensors (Basel, Switzerland), 21(4), 1210. https://doi.org/10.3390/s21041210 
2. Al-Azzam, A. F., Al-Mizeed, K. (2021). The Effect of Digital Marketing on Purchasing Decisions: A Case Study in Jordan. The Journal of Asian Finance, Economics, and Business, 8(5), 455-463. https://doi.org/10.13106/JAFEB.2021.VOL8.NO5.0455

3. Anaza, N. A. (2014). Personality Antecedents of Customer Citizenship Behaviors in Online Shopping Situations. Psychol. Mark., 31, 251-263. https://doi.org/10.1002/mar.20692

4. Anderson, S., Sin, L.G. (2020). The influence of store atmosphere on purchasing decisions and customer satisfaction: A case study at the Pacific Restaurant, Blitar. Journal of The Community Development in Asia, 3(3), 70-78. https://doi.org/10.32535/jcda.v3i3.891

5. Baciadonna, L., Cornero, F.M., Emery, N.J., Clayton, N.S. (2021). Convergent evolution of complex cognition: Insights from the field of avian cognition into the study of self-awareness. Learning \& behavior, 49(1), 9-22. https://doi.org/10.3758/s13420-020-00434-5

6. Beach, K. D., Faggella-Luby, M.N., Lembke, E.S., Satsangi, R., Schumaker, J.S., Therrien, W.J. (2021). Pedagogy, Practice, and Pride in Secondary Education: Introduction of the Critical Five. TEACHING Exceptional Children, 53(5), 338-340. https://doi.org/10.1177/00400599211010175

7. Brandtner, P., Darbanian, F., Falatouri, T., Udokwu, C. . (2021). Impact of COVID-19 on the Customer End of Retail Supply Chains: A Big Data Analysis of Consumer Satisfaction. Sustainability 13(13), 1464. https://doi.org/10.3390/su13031464

8. Bull, B. (2021). Patient satisfaction and patient experience are not interchangeable concepts. International Journal for Quality in Health Care, 33(1), mzab023. https://doi.org/10.1093/intqhc/mzab023

9. Cop, S., Alola, U.V., Alola, A.A. (2020). Perceived behavioral control as a mediator of hotels' green training, environmental commitment, and organizational citizenship behavior: A sustainable environmental practice. Bus Strat Env, 29, 3495-3508. https://doi.org/10.1002/bse.2592

10. Dinpanah, R., Naeimian, N. (2019). Relationship between Organizational Citizenship Behaviour and Empowerment among Extension Experts. Journal of Agricultural Science and Technology, 21(2), 265-275.

11. Ericson, T., Kjønstad, B.G., Barstad, A. (2014). Mindfulness and sustainability. Ecological Economics, 104, 73-79. https://doi.org/10.1016/j.ecolecon.2014.04.007

12. Gupta, B. (2012). The role of emotional intelligence in employees' organisational citizenship behaviours. Int. J. of Indian Culture and Business Management, 5, 458-471. https://doi.org/10.1504/IJICBM.2012.047415

13. Han, H., Ariza-Montes, A., Giorgi, G., Lee, S. (2020). Utilizing Green Design as Workplace Innovation to Relieve Service Employee Stress in the Luxury Hotel Sector. International journal of environmental research and public health, 17(12), 4527. https://doi.org/10.3390/ijerph17124527

14. Holmstrom, A. J., Shebib, S.J., Mazur, A.P., Mason, A.J., Zhang, L., Allard, A., Boumis, J.K. (2021). SelfConscious Emotions and Esteem Support: The Effectiveness of Esteem Support in Alleviating State Shame and Guilt. Human Communication Research, 47(21), 105-131. https://doi.org/10.1093/hcr/hqaa015

15. Horberg, E. J., Oveis, C., Keltner, D. . (2011). Emotions as moral amplifiers: an appraisal tendency approach to the influences of distinct emotions upon moral judgment. Emot. Rev, 3(3), 237-244. https://doi.org/10.1177/1754073911402384

16. Huang, Y., Li, B. (2019). Residents' awareness of family doctor contract services, the status of the contract with a family doctor, and contract service need in Zhejiang Province, China: a cross-sectional study. International journal of environmental research and public health, 16(18), 3312. https://doi.org/10.3390/ijerph16183312

17. Isturiz, R., Grant, L., Gray, S., Alexander-Parrish, R., Jiang, Q., Jodar, L., Peyrani, P., Ford, K. D., Pride, M. W., Self, W. H., Counselman, F., Volturo, G., Ostrosky-Zeichner, L., Wunderink, R. G., Sherwin, R., Overcash, J. S., File, T., Ramirez, J. (2021). Expanded Analysis of 20 Pneumococcal Serotypes Associated With Radiographically Confirmed Community-Acquired Pneumonia in Hospitalized US Adults. Clinical infectious diseases : an official publication of the Infectious Diseases Society of America, ciab375, Online ahead of print. https://doi.org/10.1093/cid/ciab375

18. Kabat-Zinn, J. (2021). The Liberation Potential of Mindfulness. Mindfulness, 12, $1555-1563$. https://doi.org/10.1007/s12671-021-01608-6

19. Karl, J. A., Fischer, R., Jose, P.E. (2021). The Development of Mindfulness in Young Adults: the Relationship of Personality, Reinforcement Sensitivity, and Mindfulness. Mindfulness 12, 1103-1114. https://doi.org/10.1 007/s12671-020-01576-3

20. Kim, S., Thibodeau, R., Jorgensen, R. S. (2011). Shame, guilt, and depressive symptoms: a meta-analytic review. Psychological bulletin, 137(1), 68-96. https://doi.org/10.1037/a0021466

21. Massari, S., Antonelli, M., Principato, L., Pratesi, C.A. (Ed.). (2021). Design Thinking to Engage Consumers in Achieving Zero Waste Food Experiences: The CEASE Framework. Springer. https://doi.org/10.1007/978-3030-54296-2_15.

22. Morin, A. J. S., Vandenberghe, C., Boudrias, J., Madore, I., Morizot, J., Tremblay, M. (2011). Affective commitment and citizenship behaviors across multiple foci. Journal of Managerial Psychology, 26(8), 716-738. https://doi.org/10.1108/02683941111181798

23. Morledge, T. J., Alexandre, D., Fox, E., Fu, A.Z., Higashi, M.K., Kruzikas, D.T., Reese, P.R. (2013). Feasibility of an online mindfulness program for stress management - a randomized, controlled trial. Ann. Behav. Med, 46(2), 137-148. https://doi.org/10.1007/s12160-013-9490-x 
24. Page, K., Graves, N. (2021). A cross-sectional study of organizational factors and their impact on job satisfaction and emotional burnout in a group of Australian nurses: infection control practitioners. BMC Health Serv Res, 21, 441. https://doi.org/10.1186/s12913-021-06477-2

25. Pfattheicher, S., and Keller, J. (2015). The watching eyes phenomenon: The role of a sense of being seen and public self-awareness. Eur. J. Soc. Psychol, 45, 560-566. https://doi.org/10.1002/ejsp.2122

26. Pham, M. T., Goukens, C., Lehmann, D. R., Stuart, J. A. (2010). Shaping customer satisfaction through selfawareness cues. Journal of Marketing Research, 47(5), 920-932. https://doi.org/10.1509/jmkr.47.5.920

27. Pourhossein, R., Mousavi, S.A., Zare Moghadam, A., Mirblok Bozorgi, A., Hassani Estelkhi, F. . (2020). Mindfulness from Theory to Therapy. Psychological Development, 8(1), 34-39.

28. Sánchez-García, J., Rodríguez, G. E., Hernández-Gutiérrez, D., Casado, P., Fondevila, S., Jiménez-Ortega, L., Muñoz, F., Rubianes, M., \& Martín-Loeches, M. . (2021). Neural dynamics of pride and shame in social context: an approach with event-related brain electrical potentials. Brain structure \& function, 226(6), 18551869. https://doi.org/10.1007/s00429-021-02296-7

29. Schuman-Olivier, Z., Trombka, M., Lovas, D. A., Brewer, J. A., Vago, D. R., Gawande, R., Dunne, J. P., Lazar, S. W., Loucks, E. B., Fulwiler, C. (2020). Mindfulness and Behavior Change. Harvard review of psychiatry, 28(6), 371-394. https://doi.org/10.1097/HRP.0000000000000277

30. Shang, X., Huang, Y., Li, B., Yang, Q., Zhao, Y., Wang, W., Liu, Y., Lin, J., Hu, C., Qiu, Y. . (2019). Residents' awareness of family doctor contract services, the status of the contract with a family doctor, and contract service need in Zhejiang Province, China: a cross-sectional study. International journal of environmental research and public health, 16(18), 3312. https://doi.org/10.3390/ijerph16183312

31. Tee, K. N., Leong, K.E., Abdul Rahim, S.S. (2021). A Self-Regulation Model of Mathematics Achievement for Eleventh-Grade Students. Int J of Sci and Math Educ, 19, 619-637. https://doi.org/10.1007/s10763-020-10076-8

32. Vago, D. R., Silbersweig, D. A. (2012). Self-awareness, self-regulation, and self-transcendence (S-ART): a framework for understanding the neurobiological mechanisms of mindfulness. Frontiers in human neuroscience, 296. https://doi.org/10.3389/fnhum.2012.00296

33. Wilcox, K., Kramer, T., Sen, S. (2011). Indulgence or self-control: a dual-process model of the effect of incidental pride on indulgent choice. J. Consum. Res., 38(1), 151-163. https://doi.org/10.1086/657606

34. Yamaguchi, S. (2021). The effect of online C2C markets on new-product-purchasing behavior: an empirical analysis of Japanese selling apps. SN Bus Econ, 1(26), 85-91. https://doi.org/10.1007/s43546-020-00022-9

35. Yang, H. X., Hu, H.X., Zhang, Y.J. et al. . (2021). A network analysis of interoception, self-awareness, empathy, alexithymia, and autistic traits. Eur Arch Psychiatry Clin Neurosci, Online ahead of print. https://doi.org/10.1007/s00406-021-01274-8

36. Yi, Y., Gong, T. (2008). The effects of customer justice perception and impact on customer citizenship behavior and dysfunctional customer behavior. Industrial Marketing Management, 37(7), 764-783. 